Original Article

\title{
Comparison of the use of neutrophil: lymphocyte count ratio (NLCR) to total leukocyte count in diagnosing appendicitis in adults with right iliac fossa pain
}

\author{
Rabindra K.C, ${ }^{1}$ Abhishek Bhattarai, ${ }^{2}$ Rakshya Joshi, ${ }^{3}$ Ashok kharel, ${ }^{1}$ Ishwar lohani, ${ }^{4}$ \\ ${ }^{1}$ Department of Surgery, Narayani samudayik Hospital, Chitwan, Nepal \\ ${ }^{2}$ Department of surgery, Chitwan medical college ,Chitwan, Nepal \\ ${ }^{3}$ Department of Gynecology and Obstetrics, Chitwan medical college, Chitwan, Nepal \\ ${ }^{4}$ Department of Surgery, Maharajgunj Medical Campus, Tribhuvan University Teaching Hospital, Nepal
}

Correspondance: Rabindra K.C, Department of Surgery, Narayani samudayik Hospital, Chitwan, Nepal

E-mail: rabindraKC01@hotmail.com

\begin{abstract}
Introduction: Diagnosis of acute appendicitis (AA) is purely based on history, examination and few laboratory investigations. However, it is often a perplexing diagnostic problem during the early stages of the disease.Failure to make an early diagnosis is a primary reason for morbidity and mortality. Elevated leukocyte count is one of the indicators of appendiceal inflammation in patients with right iliac fossa pain and most of the patients with acute appendicitis present with leucocytosis. Recently, it has been seen that the neutrophil: lymphocyte count ratio (NLCR) is a more sensitive marker than leukocytosis in patients with acute appendicitis.

Method: This is a prospective observational study conducted over a period of one year in the department of surgery at the Tribhuvan University Teaching Hospital, from September 2013 to August 2014. The clinical diagnosis of Acute appendicitis was made by history and clinical examinations and laboratory investigations. Total leukocyte count (TLC) and NLCR of patients diagnosed as AA were measured and recorded in the pro forma. Histological diagnosis was taken as the final diagnosis.

Results: A total of 106 patients were included in the study. Two third of the patients were male. Right iliac fossa tenderness was the most common sign. Ultrasound was able to diagnose acute appendicitis in $40.65 \%$ of the cases. NLCR $>3.5$ was observed in $90.56 \%$ of patients with acute appendicitis, whereas $78.3 \%$ of patients had leukocytosis only. High NLCR (5.60) is associated with complicated AA.

Conclusion: NLCR is a more sensitive laboratory parameter than TLC in patients with RIF pain to diagnose acute appendicitis. A high NLCR ratio has a high likelihood of a complicated AA.

Keywords: Appendicitis, TLC, NLCR
\end{abstract}

\section{Introduction}

Acute appendicitis is one of the most common causes of an acute abdomen requiring surgery. ${ }^{1,2}$ Lifetime risk of having acute appendicitis is $8.6 \%$ and $6.7 \%$ for men and women respectively. $^{2}$
Many times, symptoms of acute appendicitis overlap with a number of other conditions, making diagnosis a challenge, particularly in very young, elderly patients and females of reproductive age ${ }^{3}$. The classical clinical picture of AA is encountered in less than $50 \%$ of patients. ${ }^{4}$ Delayed diagnosis of appendicitis is associated, increased the incidence of 
perforation and later wound infection andpelvic abscess formation. Most frequently perforation is seen in children less than 5 years and in patients over 65 years. ${ }^{5,6}$ Commonly used Scoring system to diagnose AA uses leukocytosis as a laboratory parameter, but its sensitivity in patients with AA is $78.6 \%$ and specificity of $54.8 \% .^{7,8}$

It is a well-known fact that bacteremia is the main sequela of $\mathrm{AA}^{9}$. Leukocytosis and increased NLCR are the early indicators of bloodstream infection. ${ }^{10}$

It has been seen that a high level of NLCR $>3.5$ is more sensitive markers of bacteremia in patients with AA and has more diagnostic accuracy as compared to leucocytosis with high sensitivity and specificity. ${ }^{11}$

\section{Methods}

This is a prospective observational study was carried over a period of one year, from September 2013 to August 2014 in the Department of Surgery, Tribhuvan University Teaching Hospital Nepal. All patients with a clinical diagnosis of acute appendicitis undergoing emergency appendectomy were included in the study. Patient undergoing interval appendectomy; lacking histopathology report, age less than 16 yrs, post chemotherapy and other immunosuppressive status were excluded.

Initial evaluation of patients was done by surgery residents. The diagnosis of acute appendicitis was based on history, clinical examination, and investigation of the patients. Total leucocyte count (TLC) and NLCR of patients diagnosed as AA were measured and recorded in the proforma. The peroperative findings were recorded. Histological diagnosis was taken as the final diagnosis.

Statistical analysis was done by using Statistical Package for the Social Sciences Software (SPSS) programme for Windows $^{\circledR}$ version 20. A p-value of 0.05 was taken as statistically significant. The study was approved by the Institutional Review Board of the Institute of Medicine.

\section{Results}

Out of 106 patients included in the study, $66.9 \%$ of patients were male and $33.1 \%$ of patients were female with Male to Female ratio $2: 1$. The mean age of the patients was 29.63 (range16-82) years. Most of the patients were in the age group of 20 to 30 years (Figure 1)

Right iliac fossa (RIF) tenderness was present in all cases, whereas rebound tenderness and anorexia were seen in $82 \%$ and $80 \%$ respectively. Leucocytosis (TlC $>10500 /$ cumm) seen in $78.3 \%$ cases and neutrophilia (neutrophil $>75 \%$ ) is seen in $71.7 \%$. Neutrophil-lymphocyte ratio (NLCR) more than 3.5 is seen in $90.56 \%$ of the patients with leucocytosis and about $9.44 \%$ of the patients with NLCR more than 3.5 had normal leucocyte count. Ultrasound was able to diagnose acute appendicitis in $40.65 \%$ of the cases.

The final diagnosis of AA was based on a histopathological report. Among 106 cases, 11.32\% were uncomplicated appendicitis and $65.09 \%$ were gangrenous AA. Remaining $23.58 \%$ were suppurative AA. NLCR is above 4.0 in patients with acute suppurative appendicitis, whereas in patients with acute gangrenous appendicitis it is 5.60.

Figure 1: Age distribution of patients (in years)

\section{Age Distibution}

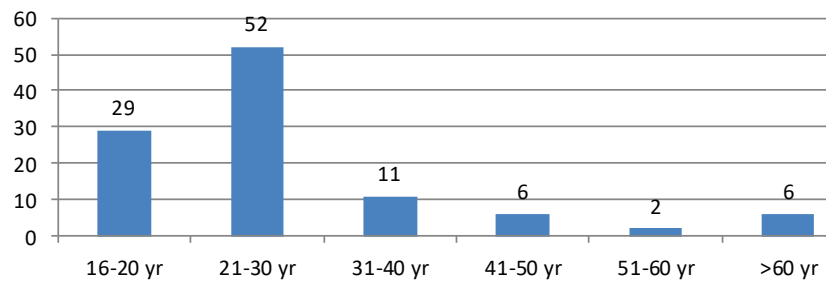

Table 1: The clinical features of the patients

$\begin{array}{lll}\text { Clinical feature } & \text { No of patients } & \text { Percentage(\%) } \\ \text { Right iliac fossa } & 106 & 100 \\ \text { tenderness } & & \\ \text { Rebound tenderness } & 87 & 82.07 \\ \text { Anorexia } & 85 & 80.18 \\ \text { Leukocytosis } & 83 & 78.3 \\ \text { Nausea/Vomiting } & 79 & 74.5 \\ \text { Migratory pain } & 68 & 64.15 \\ \text { Fever } & 24 & 22.6\end{array}$

\section{Histopathological findings}

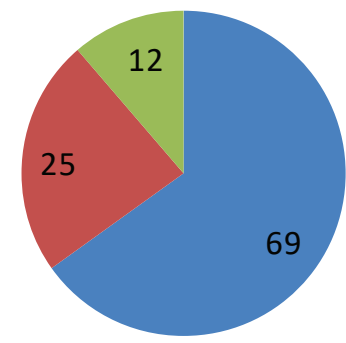

Acute appendicitis

Acute suppurative appendicitis

Acute gangrenous appendicitis

Figure 2: Histopathological findings 


\section{Discussion}

Clinical examination is still the mainstay in the diagnosis of AA. ${ }^{12}$ Different scoring system has been developed and practiced in a different part of the world to improve the diagnostic accuracy of AA. AA was found to be more common in $2^{\text {nd }}$ to $3^{\text {rd }}$ decade of life ${ }^{13}$. The exact cause of this high incidence of acute appendicitis in the young age group is still unknown but it is believed that the amount of lymphoid tissue in the submucosa of appendix increase in size and number with increasing age could be responsible for the development of AA in younger age groups. ${ }^{14}$ In this study, about $80 \%$ of patients were between age group 16 30 which declines with age in adults, which is comparable with other studies also. However, some studies showed the slight increased in the incidence of AA after the $6^{\text {th }}$ decade in both genders, suggesting that there is still a risk of having an AA in older age group, which is associated with increased risk of perforation morbidity and mortality. ${ }^{15}$

There is a range of variation in the incidence of AA among male and female sex. Some literature showed that AA was found to be more common in males whereas some others showed it is more common in female patients. This variation is similar in different part of the world. The exact cause of the incidence of this gender difference still unknown. ${ }^{15-18}$ More research is needed to better understand the gender differences in AA and molecular basis for this.

Since the last 30 years, ultrasound (USG) of the abdomen has been an important tool used in the diagnosis of appendicitis and to ruled out other differentials in patients with acute abdomen. The sensitivity and specificity of USG to diagnose AA are $69 \%-88 \%$, and $81 \%-92 \%$ respectively ${ }^{18,19}$, which is very high as compared to our result. In an emergency, for acute abdomen, resident on duty performs USG could be the reason for the low detection rates in our hospital.

Leukocytosis is considered as an important component in most of the scoring system. High leucocyte count is suggestive of initial body response towards infection

Neutrophils are the first cells of the immune system to respond in response to acute bacterial infection. As first responders, they also send out signals to other cells in the immune system to respond to infection. A change in neutrophil to lymphocyte ratio in acute infection reflects the severity of the inflammatory response in the body.

Eighty to $-85 \%$ of the patients with acute appendicitis will have leucocytosis. ${ }^{20,21}$ In this study, Leucocytosis (TlC $>10500 /$ cumm) seen in $78.3 \%$ cases and neutrophilia
( neutrophil $>75 \%$ ) is seen in $71.7 \%$.

Cutoff limit of NLCR is not universal. Some study showed NLCR of 4.3 for the diagnosis of acute appendicitis, some other reported cutoff limit of 6.84 whereas, some study reported 3.5 also to distinguish acute appendicitis from normal ones ${ }^{22-26}$. In this present study, NLCR was above 3.5 in patients with AA.

In many studies, high NLCR is suggestive of complicated AA. For this also cutoff limit is not universal. This is probably genetic factors, environmental factors also play a role in body response towards infection. Ishizuka et al. showed a cut-off value of 8.0 for NLCR to differentiate gangrenous appendicitis from catarrhal appendicitis ${ }^{27}$. Whereas Khan A.et.al. showed NLCR of $>6.36$ associated with complicated acute appendicitis. ${ }^{28}$ In this present study, NLCR of 5.60 was associated with gangrenous appendicitis suggesting that positive and strong correlation between high NLCR ratio have a high likelihood of perforation.

\section{Conclusion}

NLCR is a more sensitive laboratory parameter than TLC in patients with RIF pain to diagnose acute appendicitis. A high NLCR ratio has a high likelihood of a complicated AA.

\section{References}

1. Hesami MA, Alipour H, Nikoupour Daylami H, Alipour B, Bazargan-Hejazi S, Ahmadi A. Irrigation of abdomen with imipenem solution decreases surgical site infections in patients with perforated appendicitis: a randomized clinical trial. Iranian Red Crescent medical journal 2014; 16(4): e12732.

2. Flum DR, Koepsell TD. Evaluating diagnostic accuracy in appendicitis using administrative data. The Journal of surgical research 2005; 123(2): 257-61.

3. Kanumba ES, Mabula JB, Rambau P, Chalya PL. Modified Alvarado Scoring System as a diagnostic tool for acute appendicitis at Bugando Medical Centre, Mwanza, Tanzania. BMC surgery 2011; 11: 4.

4. Nshuti R, Kruger D, Luvhengo TE. Clinical presentation of acute appendicitis in adults at the Chris Hani Baragwanath academic hospital. International journal of emergency medicine 2014; 7(1): 12.

5. Omari AH, Khammash MR, Qasaimeh GR, Shammari AK, Yaseen MK, Hammori SK. Acute appendicitis in the elderly: risk factors for perforation. World journal of emergency surgery : WJES 2014; 9(1): 6. 
6. Bansal S, Banever GT, Karrer FM, Partrick DA Appendicitis in children less than 5 years old: influence of age on presentation and outcome. American journal of surgery 2012; 204(6): 1031-5; discussion 5.

7. Al-Gaithy ZK. Clinical value of total white blood cells and neutrophil counts in patients with suspected appendicitis: retrospective study. World journal of emergency surgery: WJES 2012; 7(1): 32.

8. Agrawal CS, Adhikari S, Kumar M. Role of serum $\mathrm{C}$-reactive protein and leukocyte count in the diagnosis of acute appendicitis in Nepalese population. Nepal Medical College journal : NMCJ 2008; 10(1): 11-5.

9. Juric I, Primorac D, Zagar Z, et al. Frequency of portal and systemic bacteremia in acute appendicitis; 2001.

10. Lowsby R, Gomes C, Jarman I, et al. Neutrophil to lymphocyte count ratio as an early indicator of blood stream infection in the emergency department; 2015.

11. Goodman DA, B Goodman C, S Monk J. Use of the neutrophil:lymphocyte ratio in the diagnosis of appendicitis; 1995.

12. Özdemir H, Ünal Özdemir Z, Sunamak O, Cambaztepe F. Which one in the diagnosis of acute appendicitis: Physical examination, laboratory or imaging? A retrospective analysis in the light of pathological results. Electronic Journal of General Medicine 2018; 15(2).

13. Khairy G. Acute appendicitis: is removal of a normal appendix still existing and can we reduce its rate? Saudi journal of gastroenterology : official journal of the Saudi Gastroenterology Association 2009; 15(3): 167-70.

14. Almaramhy HH. Acute appendicitis in young children less than 5 years: review article. Italian journal of pediatrics 2017; 43(1): 15.

15. Lee JH, Park YS, Choi JS. The epidemiology of appendicitis and appendectomy in South Korea: national registry data. Journal of epidemiology 2010; 20(2): 97-105.

16. Kumar N, Narayanan S, B S, et al. Appendicitis and appendectomy: a retrospective survey in south Indian population; 2013.

17. Stein GY, Rath-Wolfson L, Zeidman A, et al. Sex differences in the epidemiology, seasonal variation, and trends in the management of patients with acute appendicitis. Langenbeck's archives of surgery 2012; 397(7): 1087-92.
18. Mostbeck G, Adam EJ, Nielsen MB, et al. How to diagnose acute appendicitis: ultrasound first. Insights into imaging 2016; 7(2): 255-63.

19. Pinto F, Pinto A, Russo A, et al. Accuracy of ultrasonography in the diagnosis of acute appendicitis in adult patients: review of the literature. Critical ultrasound journal 2013; 5 Suppl 1: S2.

20. Saaiq M, Niaz Ud D, Jalil A, Zubair M, Shah SA. Diagnostic accuracy of leukocytosis in prediction of acute appendicitis. Journal of the College of Physicians and Surgeons--Pakistan : JCPSP 2014; 24(1): 67-9.

21. Mtimba L, Dhaffala A, Molaoa SZ. A Retrospective Analysis of Acute Appendicitis, Ruptured Appendicitis and the Level of Leukocytosis in Paediatric Surgical Patients of Nelson Mandela Central Hospital. South African journal of surgery Suid-Afrikaanse tydskrif vir chirurgie 2017; 55(2): 57.

22. Kucuk A, Erol MF, Senel S, et al. The role of neutrophil lymphocyte ratio to leverage the differential diagnosis of familial Mediterranean fever attack and acute appendicitis. The Korean journal of internal medicine 2016; 31(2): 386-91.

23. Goodman DA, Goodman CB, Monk JS. Use of the neutrophil:lymphocyte ratio in the diagnosis of appendicitis. The American surgeon 1995; 61(3): 257-9.

24. Yazar FM, Bakacak M, Emre A, et al. Predictive role of neutrophil-to-lymphocyte and platelet-tolymphocyte ratios for diagnosis of acute appendicitis during pregnancy. The Kaohsiung journal of medical sciences 2015; 31(11): 591-6.

25. Yazici M, Ozkisacik S, Oztan MO, Gursoy H. Neutrophil/lymphocyte ratio in the diagnosis of childhood appendicitis. The Turkish journal of pediatrics 2010; 52(4): 400-3.

26. Molah karim S. ROLE OF NEUTROPHIL/ LYMPHOCYTE RATIO IN DIAGNOSIS OF ACUTE APPENDICITIS; 2015.

27. Ishizuka M, Shimizu T, Kubota K. Neutrophil-tolymphocyte ratio has a close association with gangrenous appendicitis in patients undergoing appendectomy. International surgery 2012; 97(4): 299-304.

28. Khan A, Riaz M, Kelly ME, et al. Prospective validation of neutrophil-to-lymphocyte ratio as a diagnostic and management adjunct in acute appendicitis. Irish journal of medical science 2018; 187(2): 379-84. 